\title{
Voltage- and Site-Dependent Control of the Somatic Impact of Dendritic IPSPs
}

\author{
Stephen R. Williams ${ }^{1,2,3}$ and Greg J. Stuart ${ }^{1,2}$ \\ ${ }^{1}$ Division of Neuroscience, John Curtin School of Medical Research, Australian National University, Canberra, Australian Capital Territory 0200, Australia, \\ ${ }^{2}$ Institute of Physiology, University of Freiburg, D-79104 Freiburg, Germany, and ${ }^{3}$ Neurobiology Division, Medical Research Council Laboratory of \\ Molecular Biology, Cambridge CB2 2QH, United Kingdom
}

Inhibitory interneurons target specific subcellular compartments of cortical pyramidal neurons, where location-specific interactions of IPSPs with voltage-activated ion channels are likely to influence the inhibitory control of neuronal output. To investigate this, we simulated IPSPs as a conductance source at sites across the somato-apical dendritic axis (up to $750 \mu \mathrm{m}$ ) of neocortical layer 5 pyramidal neurons. Analysis revealed that the electrotonic architecture of cortical pyramidal neurons is highly voltage dependent, resulting in a significant site-dependent disparity between the amplitude, kinetics, and dendro-somatic attenuation of IPSPs generated from depolarized $(-50 \mathrm{mV})$ and hyperpolarized $(-80 \mathrm{mV})$ membrane potentials. At the soma, the time course of IPSPs evoked from depolarized potentials was greatest when generated from proximal dendritic sites and decreased as events were generated more distally, whereas the somatic time course of IPSPs evoked from hyperpolarized potentials was independent of the dendritic site of generation. This behavior resulted from the concerted actions of axo-somatic sodium channels that increased the duration of proximal dendritic IPSPs generated at depolarized potentials and distal dendritic hyperpolarization-activated channels that mediated site independence of somatic IPSP time course at hyperpolarized potentials. Functionally, this voltage-dependent control of IPSPs shaped the spatial and temporal profile of inhibition of axonal action potential firing and dendritic spike generation. Together, these findings demonstrate that the somatic impact of dendritic IPSPs is highly voltage dependent and controlled by classes of ion channels differentially distributed across axodendritic domains, directly revealing site-dependent inhibitory synaptic processing in cortical pyramidal neurons.

Key words: sodium channel; $I_{\mathrm{H}}$ channel; inhibition; patch clamp; action potential; neocortex; dendrite

\section{Introduction}

The action potential output of neurons reports the integration of EPSPs and IPSPs. Recent investigations have provided detailed, cell type-specific information on the factors that control the somatic amplitude and time course of EPSPs generated from defined dendritic sites in cortical pyramidal neurons (Magee, 2000; Williams and Stuart, 2003). Little information is available, however, on the mechanisms that shape the amplitude, time course, and efficacy of dendritically generated IPSPs.

In cortical pyramidal neurons, inhibitory synaptic contacts are targeted to specific subcellular compartments (Han et al., 1993; Buhl et al., 1994; Halasy et al., 1996; Kawaguchi and Kubota, 1997; Tamas et al., 1997; Somogyi et al., 1998), suggesting that classes of inhibitory neurons play distinctive roles in synaptic integration (Somogyi et al., 1998). The functional impact of a given inhibitory neuron will be dependent on several key factors, including the subcellular location of synaptic contacts, the properties of postsynaptic receptors, the dynamics of synaptic transmission, and the interaction of IPSPs with postsynaptic voltage-

Received April 8, 2003; revised June 9, 2003; accepted June 13, 2003.

This work was supported by grants from the Wellcome Trust and Alexander von Humboldt Stiftung. We thank Hugh Robinson for providing the design of the conductance injection amplifier.

Correspondence should be addressed to Dr. Stephen R. Williams, Neurobiology Division, Medical Research Council Laboratory of Molecular Biology, Hills Road, Cambridge CB2 2QH, UK. E-mail: srw@mrc-Imb.cam.ac.uk. Copyright $\odot 2003$ Society for Neuroscience $\quad 0270-6474 / 03 / 237358-10 \$ 15.00 / 0$ activated ion channels. Recent attention has focused on classification of the morphology and electrophysiological properties of interneuronal types (Buhl et al., 1994; Xiang et al., 1998a; Gupta et al., 2000), the target-specific molecular composition of GABA receptors (Nusser et al., 1996; Nyiri et al., 2001; Klausberger et al., 2002), and the dynamics of transmission at classes of inhibitory synapses (Gupta et al., 2000). The functional role of classes of inhibitory neurons targeting specific subcellular compartments of neurons has not been investigated in detail, although inhibitory inputs targeted to somatic and dendritic sites have been demonstrated to play an important role in the control of axonal and dendritic spike generation in hippocampal CA3 pyramidal neurons (Miles et al., 1996).

The interaction of IPSPs generated at defined dendritic sites with voltage-activated ion channels has not been explored. Voltage-activated sodium, calcium, potassium, and mixedcationic channels are nonuniformly distributed across the axodendritic domains of cortical pyramidal neurons (Häusser et al., 2000). This suggests that site-dependent recruitment of classes of ion channels will act to control the amplitude, time course, and propagation of IPSPs from the site of generation to the soma and axon. Previous studies have demonstrated voltage-dependent interaction of IPSPs in cortical pyramidal neurons with two classes of voltage-activated ion channels, the persistent sodium current $\left(I_{\mathrm{NAP}}\right)$ (Stuart, 1999) and the hyperpolarization-activated mixed 
A dendrite $110 \mu \mathrm{m}$
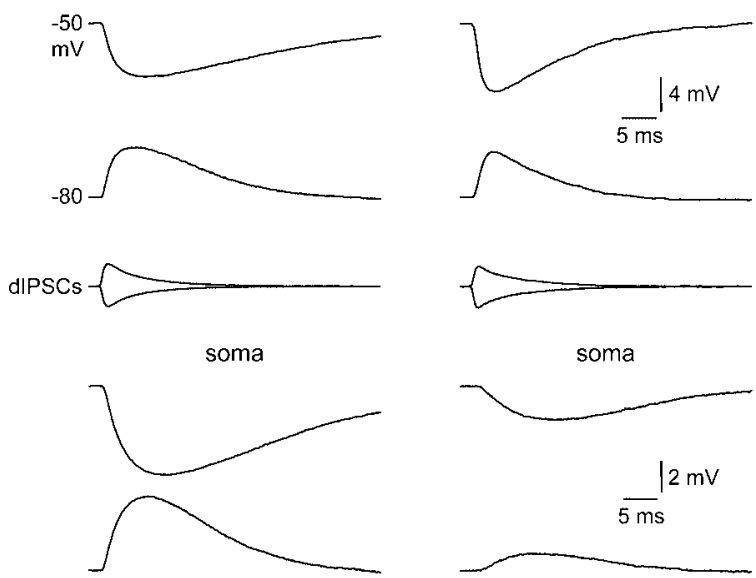

$\mathrm{B}$

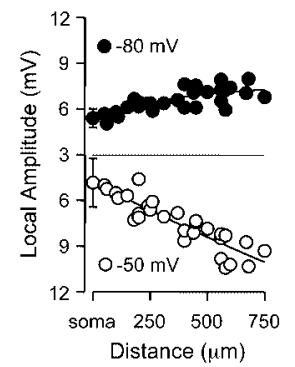

C

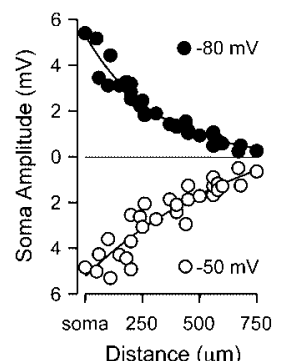

D

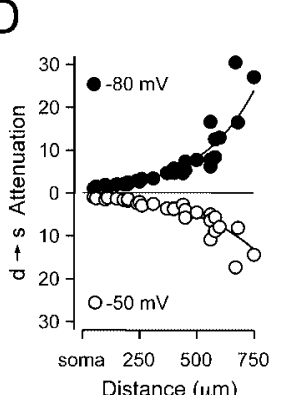

$E$

Figure 1. Site- and voltage-dependent control of dIPSP amplitude. A, Simultaneous recording of local dendritic (top traces) and somatic (bottom traces) dIPSPs generated at the indicated sites from dendritic membrane potentials of -50 and $-80 \mathrm{mV}$. The middle traces show the injected IPSC. The inset shows the somatic recording of dIPSPs generated at $750 \mu \mathrm{m}$ from the soma at higher magnification. $B, C$, Pooled data demonstrating the site and voltage dependence of local $(B)$ and somatic $(C)$ dIPSP amplitude. Somatic points represent mean $\pm S D(n=5)$. Note the site-dependent increase in the local amplitude of IPSPS generated from membrane potentials of $-50 \mathrm{mV}(O) . D$, Pooled data describing the voltage dependence of the dendro-somatic attenuation of dIPSPS. E, Ratio of the dendro-somatic attenuation of dIPSPS generated from membrane potentials of -50 and $-80 \mathrm{mV}$. Note the 1.7-fold increase in the dendro-somatic attenuation of dIPSPs generated from hyperpolarized membrane potentials. Data were fit with single exponential relationship $[B(-80 \mathrm{mV}), C, D]$ or a linear regression $[B(-50 \mathrm{mV}), E]$.

cationic current $\left(I_{\mathrm{H}}\right)$ (van Brederode and Spain, 1995). Here, we extend these findings by investigating voltage- and sitedependent interaction of IPSPs generated at defined somatodendritic sites. We find that the nonuniform distribution of $I_{\mathrm{NAP}}$ and $I_{\mathrm{H}}$ have profound consequences for the spatio-temporal integration of IPSPs. Furthermore, we directly investigate the sitedependent efficacy of IPSPs for the control of axonal and dendritic spike generation, revealing site-dependent inhibitory processing in cortical pyramidal neurons.

\section{Materials and Methods}

Wistar rats (4-6 weeks of age) were anesthetized by inhalation of halothane and decapitated, and 300- $\mu$ m-thick coronal neocortical brain slices were prepared according to guidelines approved by the Animal Experimentation Ethics Committee of the Australian National University. Slices were perfused with an oxygenated solution of composition (in mM): $125 \mathrm{NaCl}, 25 \mathrm{NaHCO}_{3}, 3 \mathrm{KCl}, 3 \mathrm{Na}$ pyruvic acid, $1.25 \mathrm{NaH}_{2} \mathrm{PO}_{4}, 2$ $\mathrm{CaCl}, 1 \mathrm{MgCl}$, and 25 glucose. Simultaneous somatic (pipettes, 2-5 M $\Omega$ ) and apical dendritic (pipettes, 8-12 M $\Omega$ ) whole-cell recordings were made from visually identified layer 5 pyramidal neurons with three current-clamp amplifiers (Dagan, Minneapolis, MN) (Williams and Stuart, 2002). Local dendritic voltage-clamp recordings were made with a patch-clamp amplifier (Axon Instruments, Foster City, CA) using online leak subtraction (P/6) (unless otherwise noted). To ensure adequate voltage control, low access resistance $(<15 \mathrm{M} \Omega$; pipettes, 6-8 M $\Omega$ ) re-
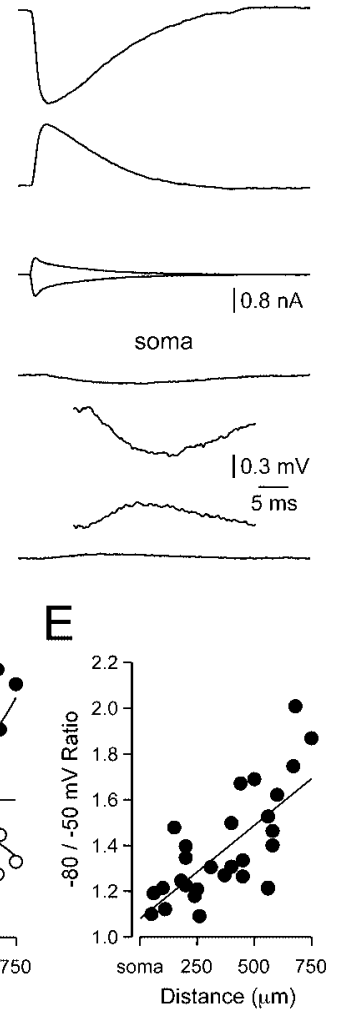

cordings were obtained, and $>95 \%$ prediction and series resistance compensation was used in the presence of lag values of $<10 \mu \mathrm{S}$. A second dendritic recording pipette (pipette separation, $<10 \mu \mathrm{m}$ ) was used to independently monitor local dendritic voltage control. Pipettes were filled with (in $\mathrm{mm}$ ): $135 \mathrm{~K}$-gluconate, $7 \mathrm{NaCl}, 10$ HEPES, $2 \mathrm{Na}_{2}$-ATP, $0.3 \mathrm{Na}_{2}$-GTP, and 2 $\mathrm{MgCl}_{2}$, pH 7.2, adjusted with $\mathrm{KOH}$ (osmolarity, $280 \mathrm{mOsm}$ ). All recordings were made at $35-37^{\circ} \mathrm{C}$. Voltage and current signals were filtered at $10-30 \mathrm{kHz}$ and acquired at $20-100 \mathrm{kHz}$ using an ITC-18 interface (Instrutech, Port Washington, NY) controlled by an Apple PowerPC.

IPSPs were simulated as linear conductance changes using a real-time conductance injection amplifier (Harsch and Robinson, 2000). The conductance source had the following characteristics: $E_{\text {dIPSP }},-64 \mathrm{mV} ; g_{\text {peak }}, 40 \mathrm{nS}$ with driving kinetics of $\tau_{\text {rise }} 0.5 \mathrm{msec}$ and $\tau_{\text {decay }}$ $5 \mathrm{msec}$. Voltage recording and current injection were implemented with independent pipettes (separated by $<10 \mu \mathrm{m}$ at dendritic sites), whereas somatic voltage responses were measured with a third pipette, allowing unbiased measurement of local dendritic and somatic dynamic IPSP (dIPSP) amplitude and time course (Williams and Stuart, 2002). The kinetics of the conductance change underlying dIPSPs was based on a synthesis of published estimates of the time course of spontaneous and unitary IPSCs in layer 5 pyramidal neurons (Xiang et al., 1998b; Stuart, 1999; Xiang et al., 2002). IPSP reversal potential was based on previous estimates obtained with perforated patch-clamp recordings from neocortical neurons of a similar developmental stage (Owens et al., 1996; Stuart, 1999; van Brederode et al., 2001; Gulledge and Stuart, 2003). Pharmacologically isolated (6-cyano-7-nitroquinoxaline-2,3dione, $10 \mu \mathrm{M}$; D-2-amino-5-phosphonovaleric acid, $100 \mu \mathrm{M}$ ) stimulus-evoked IPSPs were generated by electrical stimulation $(<0.5 \mathrm{~mA}$, $<100 \mu \mathrm{s}$ ) delivered by a patch-pipette placed under visual guidance at sites close $(\sim 10 \mu \mathrm{m})$ to either the proximal apical dendrite $(50-80 \mu \mathrm{m}$ from the soma) or the nexus of the apical dendrite $(\sim 750 \mu \mathrm{m}$ from the soma). The site of generation of stimulus-evoked IPSP was directly determined by the disparity in IPSP amplitude and rise time between somatic and dendritic recording sites (Williams and Stuart, 2002). In some experiments, axonal action potential firing was driven by somatic injection of random trains of simulated EPSPs. Simulated EPSPs were generated by multiple presentations ( $>100$ trials) of randomized trains of EPSC shaped current waveforms (frequency, I kHz; kinetics: $\tau_{\text {rise }}, 0.2$ msec; $\left.\tau_{\text {decay }}, 2 \mathrm{msec}\right)$. IPSPs rise time represents $10-90 \%$, and half-width the duration at half amplitude. Data acquisition, analysis, and curve fitting [linear regression and exponential approximation (simplex algorithm)] were performed using Axograph software (Axon Instruments). Numerical values are given in the text as mean \pm SEM, unless stated otherwise. Statistical analysis was performed with Student's $t$ test ( $\alpha=$ $0.05)$.

\section{Results}

Site and voltage dependence of dIPSP amplitude

We used simultaneous triple somatic and dendritic whole-cell recording techniques to explore the factors influencing the amplitude, time course, and dendro-somatic attenuation of IPSPs. IPSPs were simulated as a conductance source using a dynamic 
A

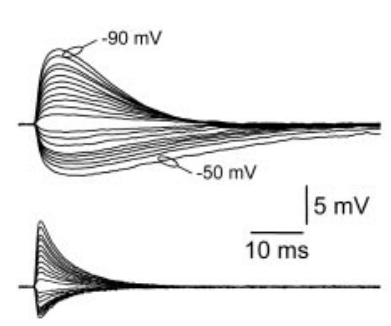

dendrite $200 \mu \mathrm{m}$
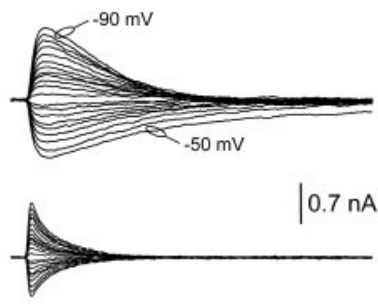

dendrite $750 \mu \mathrm{m}$

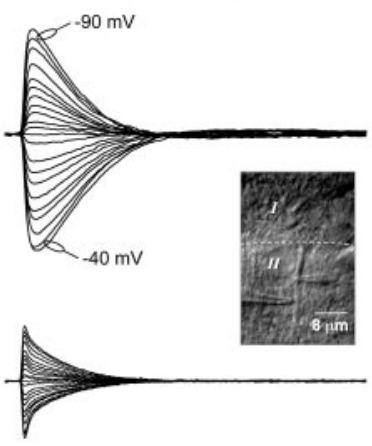

B

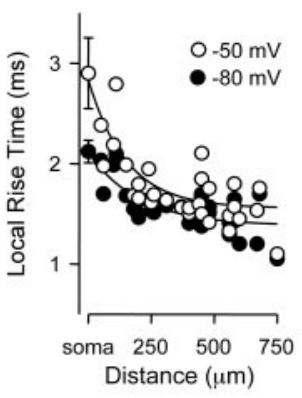

C
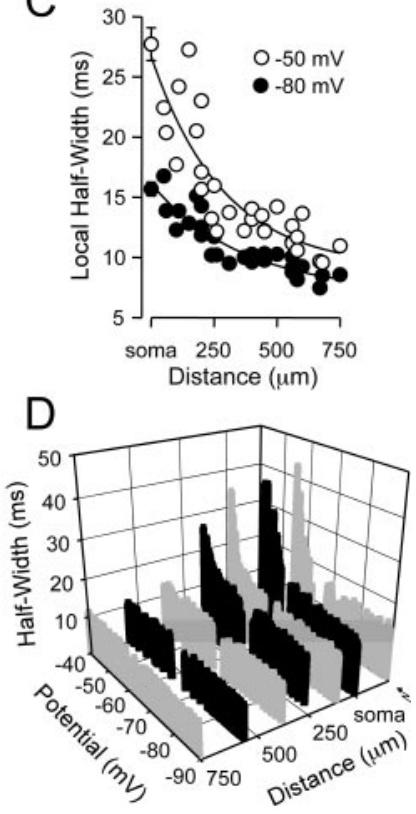

A
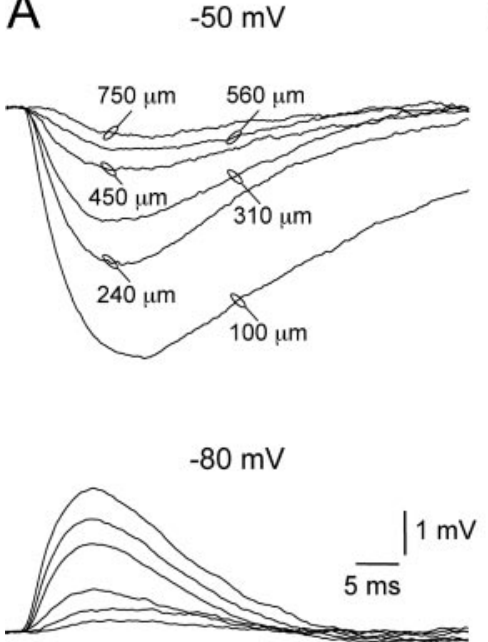

B

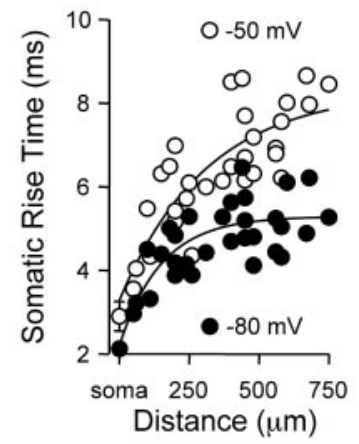

C
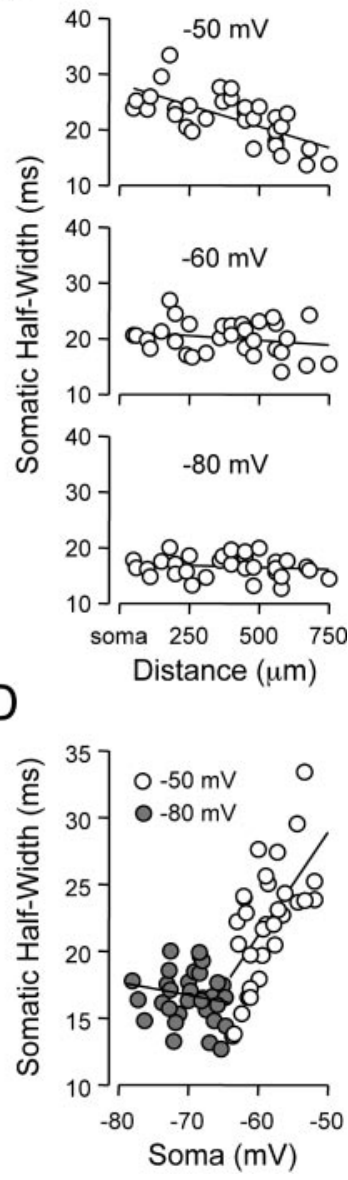

Figure 2. Kinetics of dIPSPS at site of generation. A, Voltage-dependent transformation of the local time course of dIPSPs. Voltage signals (top traces) were recorded and current-injected (bottom traces) with independent pipettes (inset, photomicrograph). Note the prolonged time course of proximally generated IPSPs generated from relatively depolarized membrane potentials. Membrane potentials have been offset for illustration. B, Pooled data illustrating the site-dependent transformation of the rise time (10-90\%) of dIPSPs generated from membrane potentials of $-50 \mathrm{mV}(\bigcirc)$ and $-80 \mathrm{mV}(\bigcirc)$. C, Pooled analysis of the time course (measured at half-amplitude) of dIPSPs generated from membrane potentials of $-50 \mathrm{mV}(\bigcirc)$ and -80 $\mathrm{mV}(\mathbf{O})$. Data in $B$ and Cwere fit with single exponentials; somatic points represent mean \pm SD $(n=5) . D$, Representative records quantifying the site- and voltage-dependent transformation of the time course (at half-amplitude) of dIPSPs. The right trace $(\rightarrow)$ represent proximal dendritically generated stimulus-evoked IPSPs. Gray scale is used to delineate data sets.

clamp (dIPSPs) at known somato-apical dendritic sites over a range of membrane potentials. Our analysis is largely focused on the disparity between the properties of dIPSPs evoked from membrane potentials hyperpolarized $(-80 \mathrm{mV})$ or depolarized $(-50 \mathrm{mV})$ to the dIPSP reversal potential $\left(E_{\mathrm{dIPSP}}\right)$ at the site of generation (Fig. 1A). The local amplitude of dIPSPs generated from depolarized membrane potentials $(-50 \mathrm{mV})$ increased linearly by up to twofold when generated from progressively distal apical dendritic sites (Fig. $1 B$, open symbols; slope of linear regression, $0.7 \mathrm{mV}$ per $100 \mu \mathrm{m}: R^{2}=0.81 ; n=30$; somatic dIPSP amplitude, $-4.8 \pm 0.8 \mathrm{mV} ; n=5$; dendritic dIPSP amplitude: $750 \mu \mathrm{m},-9.3 \mathrm{mV})$. In contrast, there was a modest (1.4-fold) site-dependent increase in the local amplitude of dIPSPs generated from hyperpolarized membrane potentials $(-80 \mathrm{mV}$ ) (Fig. $1 \mathrm{~B}$, filled symbols; somatic dIPSP amplitude, $5.4 \pm 0.3 \mathrm{mV} ; n=$ 5; dendritic dIPSP amplitude: $750 \mu \mathrm{m}, 6.8 \mathrm{mV}$ ). This voltagedependent control of local dendritic dIPSP amplitude lead to a

Figure 3. Somatic kinetics of dendritically generated dIPSPS. A, Somatic recording of dIPSPS generated from the indicated dendritic sites at local dendritic membrane potentials of -50 and $-80 \mathrm{mV}$. Note the somatic time course of dIPSPs generated from proximal dendritic sites is prolonged at depolarized membrane potentials. $B$, Pooled analysis of the site and voltage dependence of the somatic rise time (10-90\%) of dendritically generated dIPSPs. Lines represent single exponential fits, and somatic points represent mean \pm SD $(n=5)$. C, Site dependence of the somatic time course (measured at half-amplitude) of dendritically generated dIPSPs evoked from the indicated membrane potentials. Note from local dendritic membrane potentials of $-50 \mathrm{mV}$ the somatic time course of dIPSPs decreases in a distance-dependent manner, whereas from local dendritic membrane potentials of -60 and $-80 \mathrm{mV}$, the somatic time course is relatively site independent. Lines represent linear regression. D, Same data as C, plotted as a function of the somatic membrane potential achieved by setting the dendritic membrane potential to $-50 \mathrm{mV}(\bigcirc)$ or $-80 \mathrm{mV}$ (:).: Lines represent linear regression.

site-dependent disparity between the somatic amplitude of dIPSPs evoked from local membrane potentials depolarized and hyperpolarized to $E_{\mathrm{dIPSP}}$ (Fig. 1C). Calculation of the degree of dendro-somatic attenuation experienced by dIPSPs revealed that dIPSP attenuation was severe $(\sim 30$-fold at $750 \mu \mathrm{m})$ and voltage dependent (Fig. $1 D$ ), with dIPSPs generated from hyperpolarized membrane potentials experiencing up to 1.7 -fold greater dendrosomatic attenuation (Fig. $1 \mathrm{E}$; slope of linear regression, 0.08 per $\left.100 \mu \mathrm{m} ; R^{2}=0.50 ; n=29\right)$. In summary, these data indicate that dIPSPs generated from depolarized potentials have larger local amplitudes and experience less attenuation as they propagate to the soma compared with dIPSPs generated from hyperpolarized potentials, revealing that the electrotonic architecture of layer 5 pyramidal neurons is highly voltage dependent.

Site and voltage dependence of dIPSP kinetics

At the site of generation, the kinetics of dIPSPs were site and voltage dependent (Fig. 2A). Local dIPSP rise time (Fig. 2B) and 
A
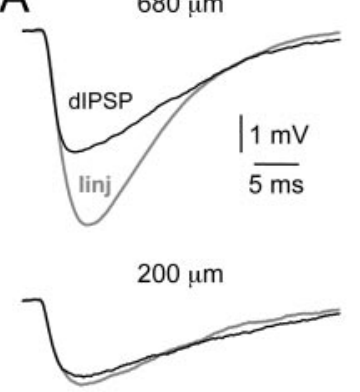

C control

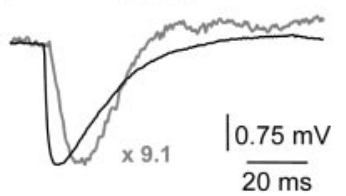

ZD $728850 \mu \mathrm{M}$

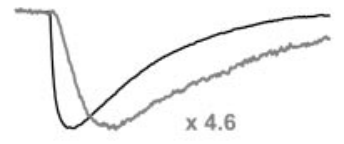

$\mathrm{B}$
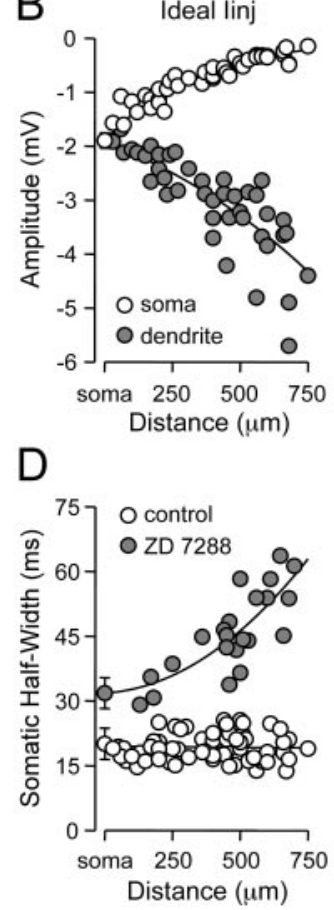

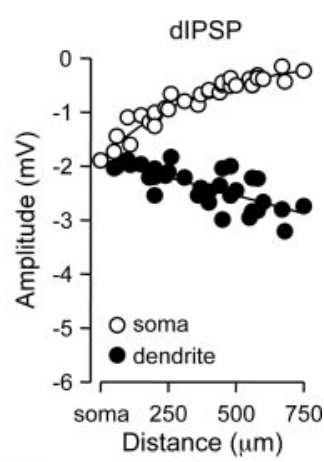

E

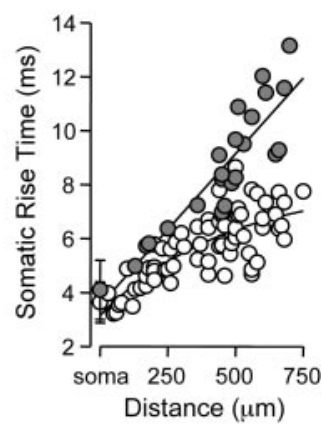

Figure 4. Properties of IPSPs simulated as ideal current sources. A, Dendritic recordings of artificial (gray) and dIPSPs generated at the indicated sites, by IPSC-shaped ideal current sources or conductance changes, respectively, from a membrane potential of $-60 \mathrm{mV} . \mathrm{B}$, Pooled analysis of the site-dependent increase in local $(\mathbf{0} / \mathbf{O})$ and decrease in somatic $(\bigcirc)$ amplitude of IPSPs generated with an ideal current source (left) or conductance source (right). C, Comparison of the somatic kinetics after peak scaling of artificial IPSPs generated at dendritic (gray; $680 \mu \mathrm{m}$ ) and somatic sites under control and after $I_{H}$ channel blockade with ZD 7288. The gray figures indicate the dendro-somatic attenuation of dendritic IPSPS. D, Relationship between somatic IPSP time course (half-width) of artificial IPSPs generated under control $(O)$ and after $I_{H}$ channel blockade (:). Lines represent a linear regression (control) and a single exponential (ZD 7288). E, Pooled data showing the site dependence of the somatic rise time $(10-90 \%)$ of artificial IPSPs under control $(O)$ and following $I_{H}$ channel blockade (:). Lines represent a single exponential (control) and a linear regression (ZD 7288). Somatic points in $B, D$, and E represent mean $\pm S D$.

half-width (Fig. 2C) became faster as dIPSPs were generated from progressively distal dendritic sites, with the half-width of dIPSPs generated at distal dendritic locations relatively constant over a wide membrane potential range ( -90 to $-40 \mathrm{mV}$ ) (Fig. $2 \mathrm{D}$ ). dIPSPs generated at proximal or somatic locations, however, showed a voltage-dependent slowing of local dIPSP half-width by up to threefold at the most depolarized subthreshold membrane potentials tested (Fig. 2D). This voltage-dependent transformation of local IPSP time course was also observed for evoked IPSPs if generated and recorded at proximal (Fig. $2 D ; n=5$ ), but not distal, apical dendritic sites $(n=3)$ (data not shown).

The site- and voltage-dependent control of local IPSP kinetics influenced the time course of dIPSPs after propagation to the soma (Fig. 3A). As predicted from cable theory, the somatic rise time of dIPSPs progressively slowed as dIPSPs were generated from increasingly distal dendritic sites (Fig. $3 B$ ). The distancedependent slowing of somatic dIPSP rise time was, however, voltage dependent and significantly greater for dIPSPs generated from depolarized membrane potentials (Fig. $3 B ;-50 \mathrm{mV}, 6.48 \pm$ $0.25 \mathrm{msec} ;-80 \mathrm{mV}, 4.74 \pm 0.15 \mathrm{msec} ; n=29 ; p<0.05$; distance from soma, $374 \pm 36 \mu \mathrm{m}$ ). The somatic half-width of dIPSPs was also highly voltage dependent. At the soma, the half-width of dIPSPs generated from hyperpolarized $(-80 \mathrm{mV})$ membrane potentials was independent of the apical dendritic site of generation (Fig. 3C; bottom graph; slope of linear regression, $-0.19 \mathrm{msec}$ per $100 \mu \mathrm{m}$ ), whereas the somatic half-width of dIPSPs generated from depolarized $(-50 \mathrm{mV})$ membrane potentials decreased in a linear manner as the site of dIPSP generation became increasingly distal (Fig. 3C; top graph; slope of linear regression, $-1.60 \mathrm{msec}$ per $100 \mu \mathrm{m}$ ). This disparity arose as a consequence of alteration of the membrane potential at the site of IPSP generation, rather than the sign (hyperpolarizing or depolarizing) of dIPSPs, because the somatic half-width of hyperpolarizing dIPSPs generated from $-60 \mathrm{mV}$ was also independent of the dendritic site of generation (Fig. $3 C$; middle graph; slope of linear regression, -0.38 msec per 100 $\mu \mathrm{m})$. These findings are in contrast to passive cable theory, which predicts (in a uniformly passive dendritic neuron) that the somatic half-width of synaptic potentials should increase when generated from increasingly distal dendritic sites (Rall, 1977). Interestingly, when the somatic half-width of dIPSPs was plotted as a function of somatic steady-state membrane potential achieved during membrane polarization at the site of dIPSP generation, a biphasic voltage-dependent relationship was revealed (Fig. 3D), with a structure reminiscent of the relationship between membrane potential and half-width exhibited by somatically generated dIPSPs (Fig. 3D, compare 2D).

Taken together, these data indicate that the amplitude and kinetics of dIPSPs at the site of generation and after propagation to the soma do not show behavior predicted from a uniformly passive system, but are indicative of interaction of dIPSPs with voltage-activated channels. This interaction acts to reduce IPSP attenuation and prolong the somatic time course of dendritic IPSPs at membrane potentials close to action potential threshold, while enhancing the attenuation and constraining the somatic time course of IPSPs generated from hyperpolarized membrane potentials.

\section{Effects of IPSP driving force}

To determine the role of changes in driving force on the properties of IPSPs described previously, we generated artificial IPSPs (aIPSPs) as ideal current sources (amplitude, $-200 \mathrm{pA} ; \tau_{\text {rise }}, 0.5$ msec; $\tau_{\text {decay }}, 5 \mathrm{msec}$ ) and compared their site-dependent properties with dIPSPs generated from membrane potentials of $-60.2 \pm 0.1 \mathrm{mV}$ (Fig. 4A). Comparison revealed that IPSPs generated as current sources $(n=42)$ displayed a pronounced distance-dependent increase in amplitude at the dendritic site of generation that was not replicated by dIPSPs $(n=32)$ (aIPSPs, $-3.0 \pm 0.14 \mathrm{mV}$ at $389 \pm 31 \mu \mathrm{m}$ from the soma; dIPSPs, $-2.38 \pm 0.06 \mathrm{mV}$ at $380 \pm 35 \mu \mathrm{m}$ from the soma; $p<0.05$ ), despite the generation of aIPSPs and dIPSPs with similar amplitudes when evoked at the level of the soma (Fig. 4B; aIPSPs, $1.90 \pm 0.14 \mathrm{mV} ; n=5$; dIPSPs, $1.89 \pm 0.04 ; n=5$ ). This sitedependent disparity emerged as a consequence of decreased driving force for dIPSPs generated from distal dendritic sites (Fig. $4 B$ ). In common with dIPSPs, however, the somatic half-width of aIPSPs was independent of the dendritic site of generation (slope of linear regression, $0.01 \mathrm{msec}$ per $100 \mu \mathrm{m}$ ) when generated from 
the same local membrane potential ( $-60 \mathrm{mV}$; Fig. $4 D$, compare $3 C)$, whereas somatic rise time increased in a distance-dependent manner as observed for dIPSPs (Fig. $4 E$, compare $3 B$ ).

\section{Interaction of dIPSPs with voltage-activated channels}

The increased duration of proximally but not distally generated dendritic dIPSPs at depolarized membrane potentials is reminiscent of the effects of the persistent sodium current $\left(I_{\mathrm{NAP}}\right)$ on the time course of somatically generated IPSPs (Stuart, 1999), whereas the independence of somatic dIPSP duration on the site of IPSP generation at hyperpolarized membrane potentials is analogous with the site independence of somatic EPSP time course generated by the hyperpolarization-activated mixed cationic current $\left(I_{\mathrm{H}}\right)$ (Magee, 1999; Williams and Stuart, 2000b). We, therefore, explored the role of $I_{\mathrm{NAP}}$ and $I_{\mathrm{H}}$ in the generation of the site- and voltage-dependent properties of dIPSPs.

To investigate the impact of $I_{\mathrm{H}}$ on the IPSP time course, we examined the effect of the specific inhibitor of $I_{\mathrm{H}}$, ZD 7288 (BoSmith et al., 1993; Harris and Constanti, 1995; Williams and Stuart, 2000b). Bath application of ZD $7288(50 \mu \mathrm{M})$ revealed a pronounced site-dependent increase of the somatic half-width of dendritically generated aIPSPs (Fig. 4C,D; control, $19.2 \pm 0.4$ msec; $n=65$; ZD 7288, $45.8 \pm 1.9$ msec; $n=23$; $p<0.05)$. Furthermore, the blockade of $I_{\mathrm{H}}$ channels dramatically increased the site dependency of the somatic IPSP rise time (Fig. $4 \mathrm{E}$; control, $5.7 \pm 0.16 \mathrm{msec} ; n=65 ; \mathrm{ZD} 7288,8.8 \pm 0.4 \mathrm{msec} ; n=23$; $p<0.05)$. These data indicate that $I_{\mathrm{H}}$ channels powerfully control both the rise and decay time course of dendritic IPSPs.

To test the involvement of $I_{\mathrm{NAP}}$ channels in the control of the amplitude and time course of dIPSPs, we investigated the effect of the sodium channel blocker TTX $(1 \mu \mathrm{M})$, bath applied either alone or in combination with the $I_{\mathrm{H}}$ channel blocker ZD 7288 (Fig. 5A). Under control conditions, the somatic time course of dIPSPs generated at proximal dendritic sites from depolarized membrane potentials was greater than those generated from hyperpolarized membrane potentials (Fig. $5 A, B$, left). In these neurons, pharmacological blockade of sodium channels with TTX significantly decreased the somatic amplitude and time course of dIPSPs generated from depolarized membrane potentials at proximal (Fig. $5 A, B$, middle; $<350 \mu \mathrm{m}$ from the soma; amplitude: control, $3.36 \pm 0.43 \mathrm{mV}$; TTX, $-2.47 \pm 0.24 \mathrm{mV} ; n=6$; $p<0.05$; half-width: control, $30.14 \pm 4.40 \mathrm{msec}$; TTX, $20.02 \pm$ 0.80 msec; $n=6 ; p<0.05$ ), but not distal, dendritic sites [ $>350$ $\mu \mathrm{m}$ from the soma; amplitude: control, $-1.56 \pm 0.20 \mathrm{mV}$; TTX, $-1.45 \pm 0.17 \mathrm{mV} ; n=10$; no statistical difference (nsd); halfwidth: control, $25.07 \pm 1.72 \mathrm{msec}$; TTX, $22.67 \pm 1.04 \mathrm{msec} ; n=$ 10 ; nsd]. dIPSPs generated from hyperpolarized membrane potentials were unaffected by TTX (Fig. $5 A, B$, middle). This result indicates that the sodium channels responsible for the voltagedependent amplification of IPSP amplitude and time course are located at sites proximal to the soma of layer 5 pyramidal neurons. In the presence of TTX, the somatic time course of dIPSPs generated from hyperpolarized membrane potentials remained site independent (Fig. $5 B$, middle). The addition of the $I_{\mathrm{H}}$ channel inhibitor ZD 7288 in the continual presence of TTX abolished the site independence of somatic dIPSP time course at hyperpolarized membrane potentials (Fig. $5 A, B$, right). This lead to a significant increase of the somatic amplitude and time course of dIPSPs generated from hyperpolarized membrane potentials (Fig. $5 B$, right; amplitude: TTX, $1.61 \pm 0.22 \mathrm{mV}$; TTX $+\mathrm{ZD}$, $2.28 \pm 0.20 \mathrm{mV} ; n=9 ; p<0.05$; half-width: TTX, $18.47 \pm 0.60$ msec; TTX + ZD, $28.98 \pm 1.55$ msec; $n=9$; $p<0.05)$. Furthermore, blockade of $\mathrm{I}_{\mathrm{H}}$ channels removed the voltage-dependent
A dendrite $150 \mu \mathrm{m}$

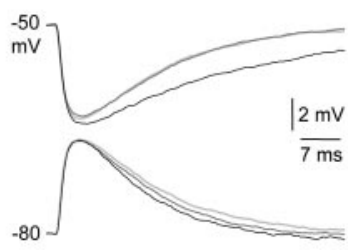

dendrite $600 \mu \mathrm{m}$
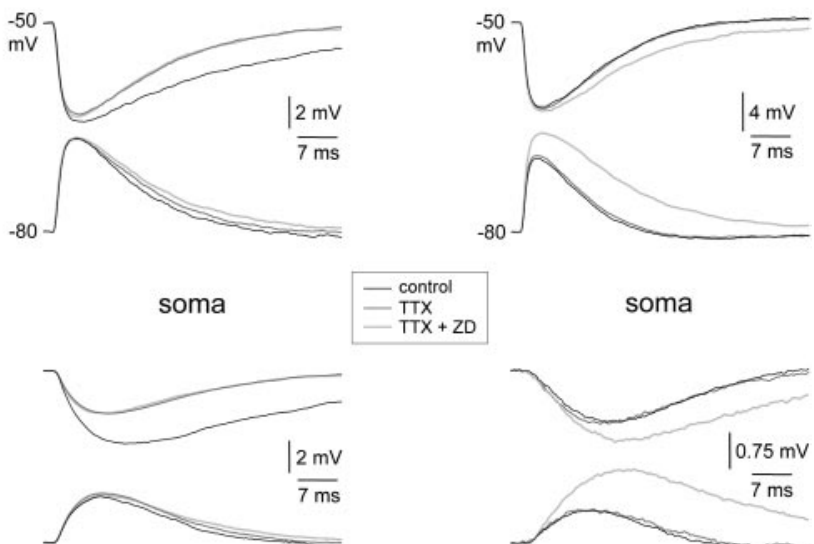

soma
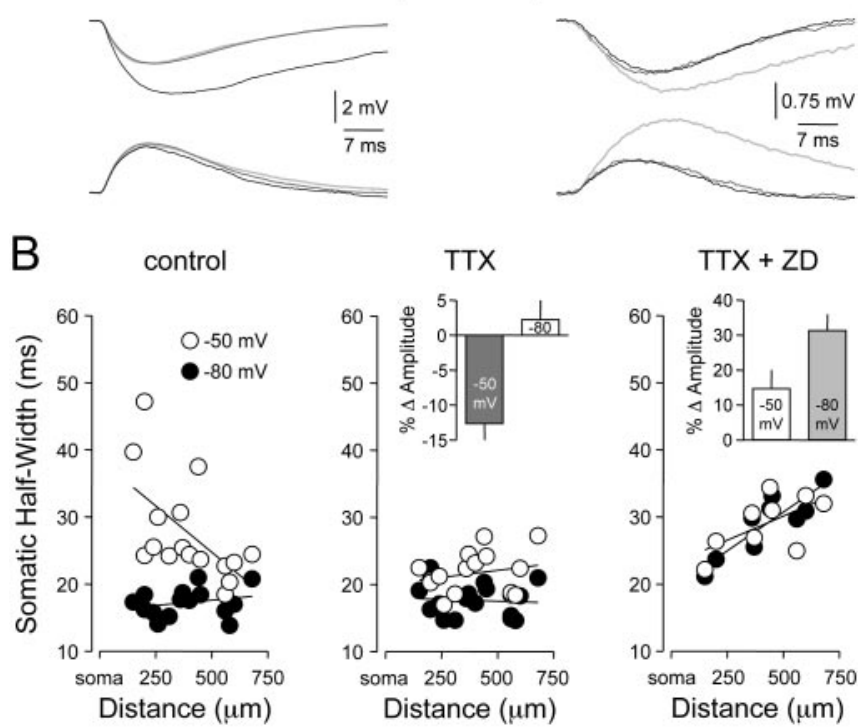

Figure 5. Dendritic $I_{\mathrm{H}}$ and axo-somatic $I_{\text {NAP }}$ shape IPSP time course. $A$, Simultaneous dendritic (top traces) and somatic (bottom traces) recording of dIPSPs generated from dendritic membrane potentials of -50 and $-80 \mathrm{mV}$ at proximal $(150 \mu \mathrm{m})$ and distal $(600 \mu \mathrm{m})$ dendritic sites under control (black), after the blockade of sodium channels with TTX (1 $\mu \mathrm{m}$; dark gray) and the coblockade of sodium and $I_{H}$ channels with TTX and ZD 7288 (50 $\mu \mathrm{m}$; light gray). $B$, Site dependence of the somatic time course (half-width) of dendritic dIPSPs generated from $-50(\bigcirc)$ and $-80 \mathrm{mV}(\bigcirc)$ under the three experimental conditions. Note the coblockade of sodium and $I_{H}$ channels abolishes the voltage dependence of the somatic time course of dIPSPS. The insets show pooled analysis of percentage changes in the somatic amplitude of dIPSPs at -50 and $-80 \mathrm{mV}$ after the application of TTX (middle; relative to control) and the coapplication of TTX and ZD 7288 (right; relative to TTX alone).

disparity of dIPSP dendro-somatic attenuation (data not shown). Together, these data indicate that the amplitude, time course and dendro-somatic attenuation of dIPSPs are controlled by an interaction of dIPSPs with voltage-activated sodium and $I_{\mathrm{H}}$ channels.

As an independent verification of the role of $I_{\mathrm{H}}$ in the control of inhibitory synaptic potentials, we tested whether IPSPs were capable of directly activating $I_{\mathrm{H}}$ channels. Electrophysiological and immunohistochemical data have revealed that $I_{\mathrm{H}}$ channels have a predominant distal apical dendritic locus (Santoro et al., 1997; Magee, 1998; Williams and Stuart, 2000b; Berger et al., 2001; Lorincz et al., 2002). Accordingly, we made local dendritic whole-cell voltage-clamp recordings from distal apical dendritic sites $(530 \pm 42 \mu \mathrm{m}$ from the soma; $n=9)$ and used exponential fits to dIPSPs generated and recorded at these dendritic sites as hyperpolarizing voltage commands (Fig. 6). Under voltage clamp, IPSP-shaped voltage commands evoked time-dependent inward currents in a voltage-dependent manner that activated during the rising phase of command IPSPs, showed a delay to peak, and decayed more slowly than the command voltage (Fig. $6 A$ ). These inward currents were sensitive to bath application of 
A

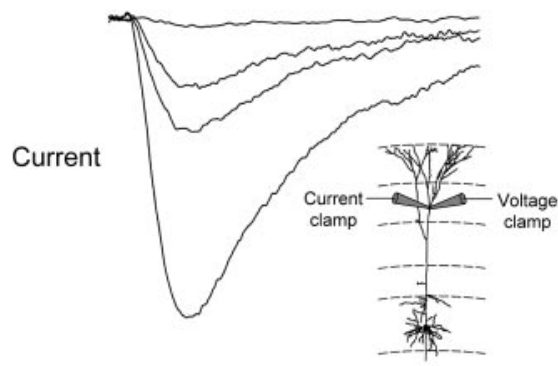

ZD $7288(50 \mu \mathrm{M})$
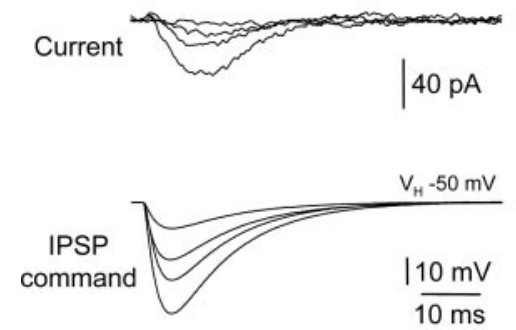

B
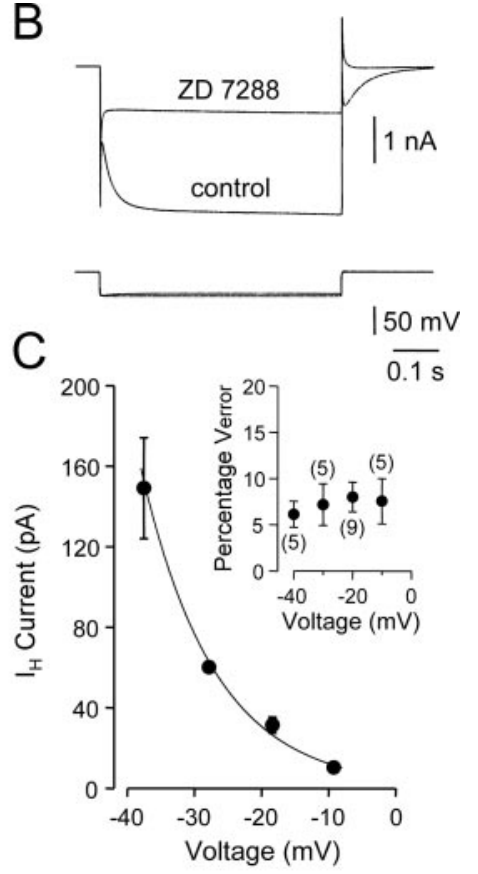

Figure 6. Activation of dendritic $I_{H}$ by IPSP waveforms. $A$, Local dendritic voltage-clamp $\left(V_{H},-50 \mathrm{mV}\right)$, leak subtracted currents generated in response to IPSP-shaped waveforms under control (top traces) and after the application of ZD 7288 (50 $\mu \mathrm{M}$; middle traces). Voltage control was monitored with a second dendritic pipette (bottom traces) in current-clamp mode. The experimental arrangement is shown in the inset. B, ZD 7288-sensitive, nonleak subtracted, time-dependent currents generated in response to $-40 \mathrm{mV}$ voltage steps (top traces). The bottom traces show the membrane potential achieved during voltage steps. C, Pooled data demonstrating the voltage dependence of $I_{H}$ activity generated during IPSP waveforms (all recordings $>500 \mu \mathrm{m}$ from the soma); points represent mean $\pm S E M$. The line represents an exponential fit to the data. The inset shows the percentage voltage error between the clamp command voltage and recorded voltage responses under current clamp; the number of tested neurons is indicated.

the $I_{\mathrm{H}}$ channel inhibitor ZD 7288 (Fig. 6A, middle), as were timedependent inward currents generated in response to long hyperpolarizing voltage steps (Fig. 6B). The effectiveness of voltage clamp was monitored with a separate dendritic recording pipette used to track local dendritic voltage (Fig. 6A, bottom). Analysis of neurons with adequate voltage control (Fig. 6 C, inset; $<20 \%$ measured voltage error) revealed that the amplitude of local dendritic $I_{\mathrm{H}}$ activated by IPSPs increased exponentially with IPSP command peak voltage (Fig. 6C). These data provide direct evidence that dendritic $I_{\mathrm{H}}$ channels can be recruited during IPSPs, independently verifying the ZD 7288 sensitivity of the amplitude, rise, and decay kinetics of IPSPs.

\section{Efficacy of dendritic inhibition}

The pronounced dendro-somatic attenuation of dIPSPs reported here (Fig. 1) suggests that inhibitory inputs located at distal dendritic sites may have little direct control of axonal action potential generation. To investigate the inhibitory efficacy of IPSPs generated at different locations, random patterns of action potential firing (average rate, $14.7 \pm 0.9 \mathrm{~Hz} ; n=21$ ) were evoked by randomized trains of simulated somatic EPSPs (see Materials and Methods) and dIPSPs generated at defined somato-dendritic sites (Fig. 7A). dIPSPs generated at the soma transiently suppressed action potential firing (reduced by $95.5 \pm 2.8 \%$ in the 10 msec period after dIPSC onset; $n=6$ ), followed by a rebound increase in firing rate (increased by $44.3 \pm 4.5 \%$ in a $20 \mathrm{msec}$ period starting $30 \mathrm{msec}$ after dIPSC onset). These effects were captured by peristimulus time histograms of action potential firing (Fig. 7B, top). When generated at distal dendritic sites (598 \pm

$25 \mu \mathrm{m}$ from the soma; $n=4$ ), however, dIPSPs reduced action potential firing by only $43.2 \pm 6.7 \%$ in the $10 \mathrm{msec}$ period after dIPSC onset (Fig. 7B, bottom). Pooled analysis revealed that the efficacy of inhibition decreased exponentially as dIPSPs were generated from progressively distal sites (Fig. 7C).

To explore the voltage dependence of action potential inhibition by dIPSPs, we generated action potentials by brief somatic current pulses $(10 \mathrm{msec})$ at variable times ( $\pm 90 \mathrm{msec} ; 10 \mathrm{msec}$ intervals) relative to dIPSPs onset (Fig. 8). At the soma $(n=5)$, dIPSPs inhibited action potential firing over a wide time window when generated from depolarized membrane potentials $(-55 \mathrm{mV})$ (Fig. $8 \mathrm{~A}$ ). The time window of inhibition, however, narrowed with membrane hyperpolarization, such that from membrane potentials $(-65 \mathrm{mV})$ close to $E_{\text {dIPSP }}$ somatic dIPSPs were only capable of inhibiting action potential firing when generated coincidentally with excitatory input (Fig. $8 \mathrm{~A}$, bottom). The spatial profile of inhibition was found to be highly voltage dependent (Fig. 8A, $B$; $n=16$ dendritic recording sites). From depolarized membrane potentials $(-55$ $\mathrm{mV}$ ) dIPSPs were capable of inhibiting action potential firing when generated over a wide dendritic territory (up to $560 \mu \mathrm{m}$ from the soma) (Fig. $8 \mathrm{~B}$, top). In contrast, dIPSPs generated from membrane potentials $(-65 \mathrm{mV})$ close to $E_{\mathrm{dIPSP}}$ only inhibited action potential firing when generated over a proximal dendritic region (up to 220 $\mu \mathrm{m}$ from the soma) (Fig. $8 \mathrm{~B}$, bottom). In these experiments, both the somatic and apical dendritic membrane potential at the site of dIPSP generation were controlled by DC injection to control for the effect of changes of synaptic efficacy mediated by alterations of dIPSP driving force. Despite the diminishing direct impact on axonal action potential initiation, however, distal dendritic dIPSPs could effectively reduce the amplitude of backpropagating action potentials (Fig. $8 \mathrm{~A}$, inset).

These data indicate that the temporal and spatial profile of inhibition of action potential initiation by dendritic IPSPs is voltage dependent. In accordance with our observations of the voltage-dependent control of dIPSP amplitude and time course and the spatial profile of inhibition of random action potential firing, these data demonstrate that dIPSPs are most efficacious (temporally and spatially) when generated from depolarized membrane potentials.

\section{Impact on dendritic excitability}

The voltage-dependent control of action potential firing by dendritic IPSPs indicates that the spatio-temporal profile of inhibitory synaptic processing in cortical pyramidal neurons is dynamically regulated and suggests that the functional role of distal dendritic IPSPs may be restricted to control of local dendritic excitability. Previous findings have revealed that distal dendritic excitatory inputs lead to the generation of dendritic spikes in cortical pyramidal neurons (Schiller et al., 1997; Stuart et al., 1997; Larkum et al., 2001; Williams and Stuart, 2002). To test 
A

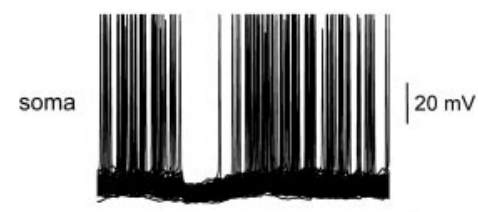

dIPSCs

$10.5 \mathrm{nA}$

distal dIPSPs
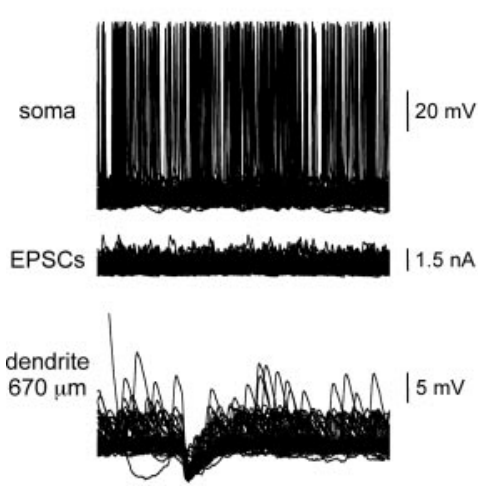

dIPSCs

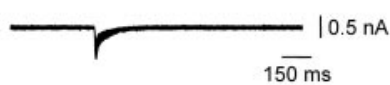

B

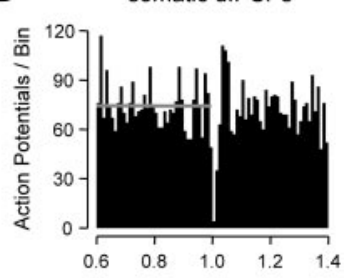

distal dIPSPs

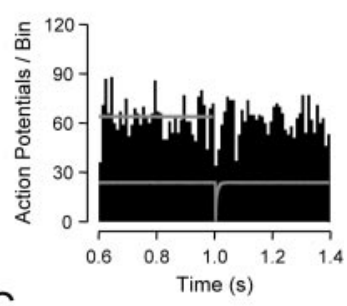

C

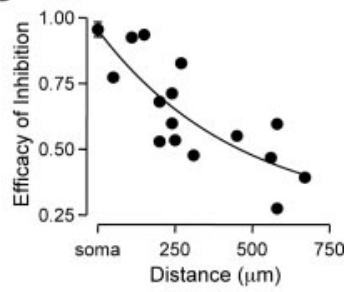

Figure 7. Efficacy of dendritic inhibition. $A$, Superposed records $(n=100)$ of action potential firing evoked by somatic injection of random EPSC waveforms is strongly inhibited by somatic (top traces), but not distal dendritic $(670 \mu \mathrm{m})$, dIPSPs (middle traces). B, Efficacy of inhibition of axonal action potentials by dIPSPs generated at somatic and distal dendritic sites. Peristimulus time histograms of action potential firing rate per $10 \mathrm{msec}$ bin illustrate pooled results for dIPSPs generated from somatic $(n=6)$ and distal dendritic sites ( $>500 \mu \mathrm{m}$ from the soma; $n=4)$. The average time course of dIPSCs is shown in gray. Horizontal gray lines indicate the average firing rate before dIPSC onset. C, Site dependence of the efficacy of inhibition. Points represent the difference between pre-dIPSC mean and nadir firing rates for individual neurons. Data for somatic sites are shown as mean \pm SD $(n=6)$. The line represents an exponential fit to the data.

whether dIPSPs were capable of inhibiting the generation of these regenerative events, we evoked dendritic spikes by the delivery of brief current pulses (10 msec; $\pm 90 \mathrm{msec} ; 10 \mathrm{msec}$ intervals) at distal dendritic sites (dendritic recordings, $560 \pm 15 \mu \mathrm{m}$ from the soma; $n=7$ ) before and after dIPSPs (Fig. $9 A$, left). To examine the functional impact of this form of inhibition, we simultaneously recorded bursts of somatic action potentials generated by the forward propagation of dendritic spikes to the axon (Schiller et al., 1997; Larkum et al., 2001; Williams and Stuart, 2002) (Fig. $9 \mathrm{~A}$, right). dIPSCs delivered at the site of dendritic spike generation inhibited the initiation of dendritic spikes over a $20 \mathrm{msec}$ time window (Fig. 9A). At the level of the soma, the time window of inhibition of axonal action potentials triggered by the forward propagation of dendritic spikes was narrow and broadly voltage independent (Fig. 9B). Interestingly, dIPSPs not only blocked dendritic spike initiation but could also sculpt the local time course of dendritic spikes (Fig. 9A, left; $-10 \mathrm{msec}$ trace). This acted to decrease the envelope of dendritic depolarization reaching the soma, inhibiting the generation of axonal action potentials (Fig. 9B). We directly compared the time window of inhibition of axonal action potential output by dIPSPs evoked at somatic or distal dendritic sites during dendritic spike generation (Fig. 9B). Time windows were found to only differ when dIPSPs were generated from relatively depolarized membrane potentials $(-55 \mathrm{mV})$, where somatic dIPSPs were capable of inhibiting ac- tion potential firing over a relatively wide time window, an action that reflects the voltage-dependent amplification of dIPSP time course of somatic and proximal dendritic IPSPs (Fig. $3 A-C$ ).

\section{Discussion}

Central neurons integrate synaptic potentials generated from sites widely distributed across their dendritic tree. The integrative operations of neurons with large dendritic arbors, such as layer 5 neocortical neurons are, therefore, complex because the impact of distal dendritic inputs on axonal action potential output will be modified by the passive and active properties of the dendritic tree. Here, we demonstrate that the somatic impact and inhibitory efficacy of dendritically generated IPSPs are highly site and voltage dependent, adding an increased level of complexity to the integrative operations of neocortical pyramidal neurons.

The somatic impact of dendritic IPSPs was investigated by the generation of simulated IPSPs, modeled as linear conductance sources with uniform amplitude, kinetics, and reversal potential at defined somato-dendritic sites. The use of inhibitory conductance with uniform kinetics and reversal potential was justified for the following reasons. Single action potential-evoked unitary IPSPs are mediated by the activation of $\mathrm{GABA}_{\mathrm{A}}$ receptors for all classes of cortical target-specific interneurons, except neurogliaform cells (Tamas et al., 2003). Although the subsynaptic kinetics of IPSCs targeted to specific subcellular compartments of neurons are unclear, recent investigation has revealed only subtle differences in the somatic kinetics of unitary IPSCs generated by classes of interneurons that target proximal or distal dendritic sites of layer 5 neocortical pyramidal neurons (Xiang et al., 2002). The $\mathrm{E}_{\mathrm{GABA}}$ has been reported to be similar at somatic and apical dendritic sites of neocortical pyramidal neurons (van Brederode et al., 2001; Gulledge and Stuart, 2003).

We find that interaction of dIPSPs with two classes of voltageactivated channels, $I_{\mathrm{NAP}}$ and $I_{\mathrm{H}}$, control their somatic impact in three key ways: (1) IPSP attenuation was $\sim 1.7$-fold greater for dIPSPs generated from hyperpolarized $(-80 \mathrm{mV})$ compared with depolarized $(-50 \mathrm{mV})$ membrane potentials; (2) IPSPs generated from depolarized membrane potentials had significantly longer durations at the soma; and (3) when generated from hyerpolarized membrane potentials, the time course of IPSPs at the soma was relatively independent of the site of IPSP generation.

\section{Interaction of IPSPs with $I_{\mathrm{NAP}}$}

A number of previous studies have shown that the amplitude and time course of EPSPs in cortical pyramidal neurons can be amplified via voltage-activated sodium channels (Deisz et al., 1991; Schwindt and Crill, 1995; Stuart and Sakmann, 1995; Lipowsky et al., 1996; Andreasen and Lambert, 1999; Williams and Stuart, 1999). Because this amplification is dependent on the steadystate membrane potential before EPSP onset and is associated with a significant slowing of the EPSP time course, it has been suggested that the voltage-activated sodium channels underlying EPSP amplification are of the persistent type, $I_{\mathrm{NAP}}$. Recent work has also shown that deactivation of $I_{\mathrm{NAP}}$ leads to amplification of somatic IPSPs (Stuart, 1999). Consistent with this, we observed that the amplification of somatic and proximal dendritic dIPSPs at depolarized, but not hyperpolarized, membrane potentials was sensitive to the sodium channel blocker TTX. $I_{\text {NAP }}$ is thought to result as a consequence of fast-inactivating sodium channels entering a noninactivating gating mode or as a product of the channel gating scheme (Alzheimer et al., 1993; Taddese and Bean, 2002). The observation that TTX-sensitive amplification of IPSPs occurred only for events generated from somatic and proximal 
A
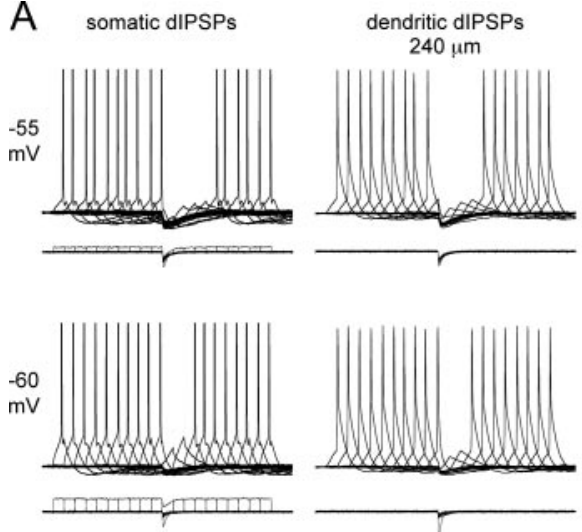

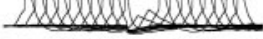
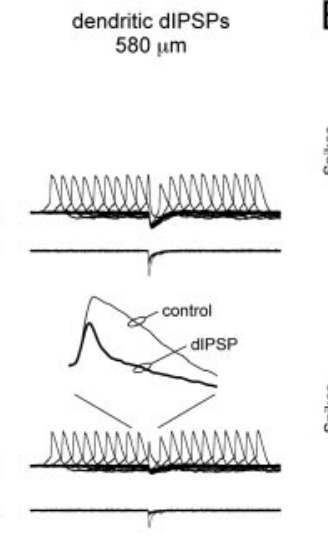

B
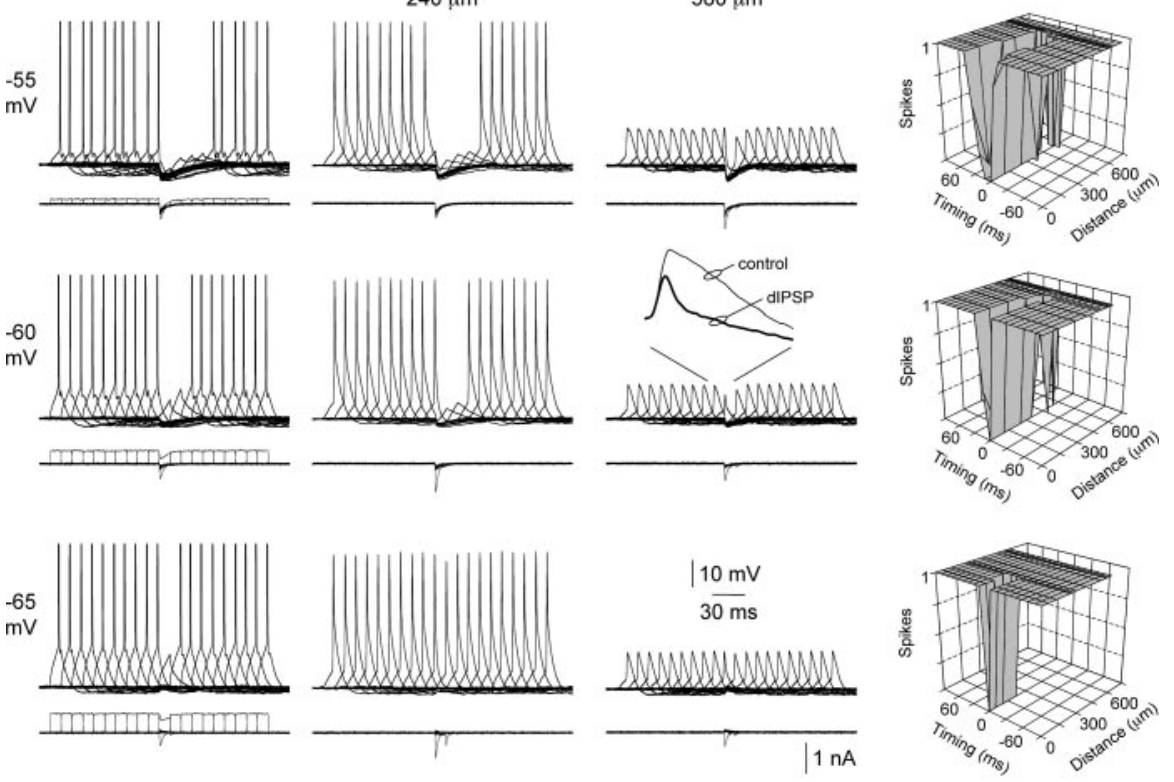

Figure 8. Voltage and site dependence of dendritic inhibition. $A$, Overlain records of single action potential firing evoked by short somatic current steps, offset in time by $10 \mathrm{msec}$, recorded at somatic (left), proximal (middle), and distal (right) dendritic sites. dIPSPs, generated at the indicated sites, suppress axonal action potential initiation over a time window defined by the site of dIPSP generation (compare panels horizontally) and membrane potential (compare panels vertically). The inset shows the effects of dIPSPs on the waveform of backpropagating action potentials. Somatic action potentials have been clipped. B, Summary plots describing the relationship between the time window of inhibition and site of dIPSP generation for local membrane potentials of $-55,-60$, and $-65 \mathrm{mV}$. Timing $=0$ represents coincidence of somatic current step and dIPSC onset. Note from the most hyperpolarized membrane potential dendritic inhibition is relatively ineffective.
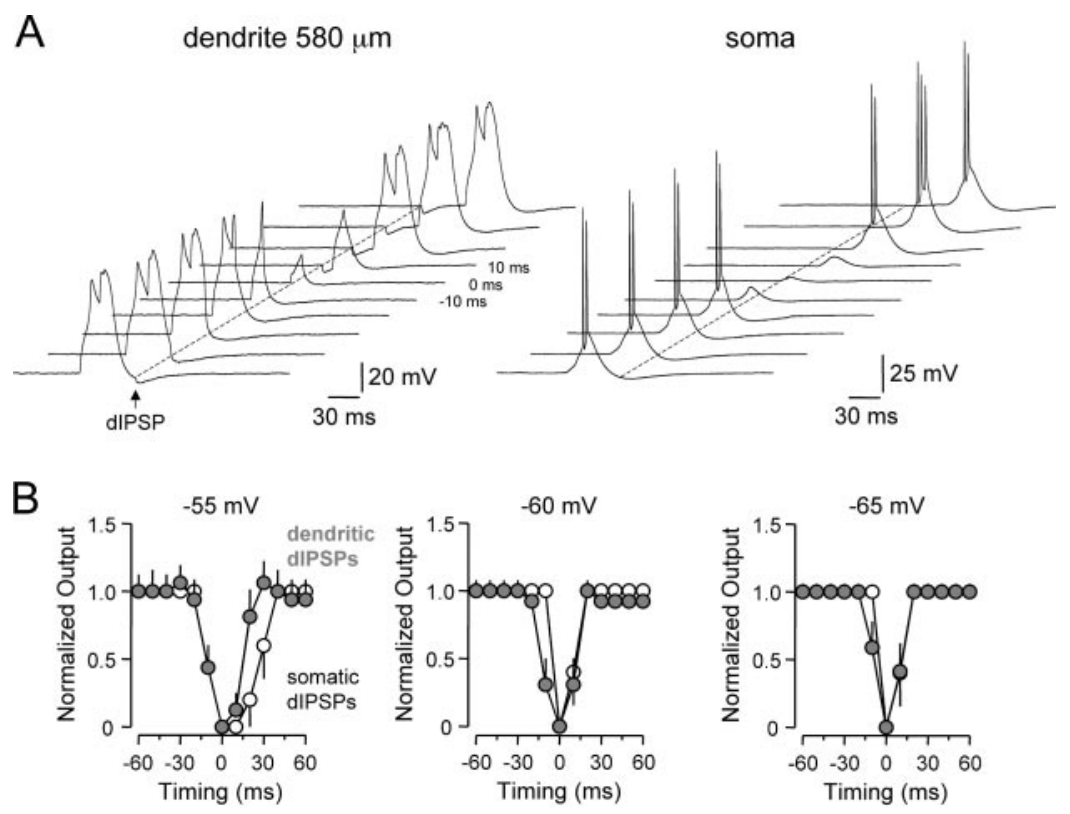

Figure 9. Voltage-dependent inhibition of dendritic spike initiation. A, Tiled records of dendritic spike firing evoked by short dendritic current steps (from $-55 \mathrm{mV}$ ), offset in time by $10 \mathrm{msec}$, recorded simultaneously at dendritic (left) and somatic (right) sites. dIPSPs generated at the dendritic site sculpt and suppress dendritic spike generation and consequent axonal action potential initiation. Timing $=0$ represents coincidence of the dendritic current step and dIPSC onset. B, Comparison of the time window for inhibition of normalized axonal spike output by dIPSPs. Open symbols show the time window for suppression of axonal spike generation by somatically generated dIPSPs. The gray symbols show the time window for suppression of axonal action potential firing, generated as a consequence of the forward propagation of dendritic spikes, by dendritic dIPSPs. Data are shown for three membrane potentials $(-55,-60$, and $-65 \mathrm{mV}$ ). Points represent normalized mean \pm SEM. Note the time window for inhibition of neuronal output is significantly longer for somatically generated dIPSPs only at the most depolarized membrane potential tested. dendritic sites suggests that the sodium channels involved in IPSP amplification have a perisomatic distribution. The somato-dendritic distribution of sodium channels is, however, uniform in neocortical layer 5 pyramidal neurons (Stuart and Sakmann, 1994; Williams and Stuart, 2000a). Furthermore, the density of sodium channels located within the axon initial segment is thought to be similar to that of the soma, although there is an increase (approximately twofold) in density at more remote axonal sites (Colbert and Pan, 2002). Intriguingly, however, the voltage of half-maximal activation of sodium channels in the distal initial segment is shifted in the hyperpolarized direction (by $\sim 7 \mathrm{mV}$ ), a property that has been suggested to underlie the preferential axonal initiation site of action potentials (Colbert and Pan, 2002). Because only a small fraction of sodium channels enter the persistent gating state at any one time (Alzheimer et al., 1993; Taddese and Bean, 2002), a negative shift in the activation curve of sodium channels would be expected to increase $I_{\mathrm{NAP}}$, an effect that would amplify the time course of synaptic events generated at sites electrotonically proximal to the axon. Our experimental data, however, indicate that distal dendritic dIPSPs are not amplified at depolarized membrane potentials even when challenged with changes in dendritic membrane potential that far exceed the reported shift of the activation curve for initial segment sodium channels (Fig. 2A). In fact, amplification of proximal dIPSPs at depolarized potentials was only apparent when the local depolarization at the site of dIPSP generation was of sufficient magnitude to bring the axosomatic membrane into a range for the activation of $I_{\mathrm{NAP}}$ (Fig. $3 D$ ). We, therefore, propose that amplification of proximally generated IPSPs results as a consequence of a high density of sodium channels located at axonal sites distal to the initial segment (Williams and Stuart, 1999), rather than because of a shift in the voltage dependence of activation. Furthermore, because distal IPSPs were not significantly amplified locally at depolarized potentials, we find no support for the notion of a predominant apical dendritic distribution of $I_{\text {NAP }}$ (Crill, 1996), which has been suggested to underlie the selective amplification of apical dendritically generated excitatory synaptic inputs (Oviedo and Reyes, 2002).

\section{Interaction of IPSPs with $I_{\mathrm{H}}$}

The role of dendritic $I_{\mathrm{H}}$ channels in the control of IPSP amplitude and kinetics was 
complex, influencing both local dendritic as well as somatic IPSP amplitude and time course, and also the dendro-somatic attenuation of IPSPs generated from relatively hyperpolarized ( -60 to $-80 \mathrm{mV}$ ) membrane potentials. Furthermore, the pharmacological blockade of $I_{\mathrm{H}}$ channels resulted in an unmasking of IPSP amplification by $I_{\mathrm{NAP}}$, revealing in common with other neuronal types that the activation range of $I_{\mathrm{H}}$ overlaps with $I_{\mathrm{NAP}}$ and that these currents operate cooperatively (Williams et al., 2002).

Previous findings have demonstrated that $I_{\mathrm{H}}$ acts to normalize the somatic time course and temporal summation of apical dendritic EPSPs, because of a distance-dependent increase in $I_{\mathrm{H}}$ channel density (Santoro et al., 1997; Magee, 1998, 1999; Williams and Stuart, 2000b; Berger et al., 2001; Lorincz et al., 2002). Because this mechanism compensates for the distancedependent effects of cable filtering on the time course and temporal integration of synaptic potentials, it has been suggested to simplify the integrative operation of central neurons (Magee, 2000). We reveal that the somatic time course of dIPSPs is independent of the apical site of generation when generated from relatively hyperpolarized membrane potentials. From depolarized membrane potentials $(-50 \mathrm{mV})$, however, where few $I_{\mathrm{H}}$ channels are available for activation (Williams and Stuart, 2000b; Berger et al., 2001), normalization of the somatic time course of IPSPs was found to break down. Because the membrane potential of central neurons in vivo is likely to be depolarized under activated states (Pare et al., 1998; Steriade et al., 2001), our findings indicate that $I_{\mathrm{H}}$-mediated normalization of somatic EPSP and IPSP time course will be of importance only under conditions in which the dendritic membrane potential is relatively hyperpolarized.

\section{Control of excitability}

The site- and voltage-dependent interaction of IPSPs with voltage-activated ion channels influenced their inhibitory efficacy. At depolarized membrane potentials, the voltagedependent amplification of somatic and proximal dendritic IPSP amplitude and time course by $I_{\mathrm{NAP}}$, combined with a reduction in dendro-somatic IPSP attenuation because of the deactivation of $I_{\mathrm{H}}$, ensured that the time window and spatial profile of inhibition of axonal action potentials were greatest when apical dendritic dIPSPs were generated from membrane potentials close to action potential initiation threshold. In contrast, IPSPs generated from potentials close to IPSP reversal potential were found to be capable of inhibiting axonal action potential firing only when generated from proximal dendritic sites at times coincident with excitatory input. Because IPSPs generated from potentials close to the reversal potential act predominately by shunting the membrane conductance, these findings can be explained by the disparity between the spatial profile of the dendro-somatic spread of changes in voltage and conductance (Koch et al., 1990). Finally, activation of $I_{\mathrm{H}}$ at hyperpolarized membrane potentials will act to enhance dendro-somatic IPSP attenuation and normalize somatic IPSP half-width, limiting the depolarization of the soma and axon by distal dendritic IPSPs generated at membrane potentials hyperpolarized to IPSP reversal. Together, these findings indicate that the control of neuronal output by dendritic IPSPs will be determined in a voltage-dependent manner, which would be expected to limit the excitatory action of depolarizing dendritic IPSPs (Gulledge and Stuart, 2003), while maximizing the somatic impact and inhibitory efficacy of hyperpolarizing IPSPs evoked from membrane potentials near action potential firing threshold.

Inhibitory operations in layer 5 pyramidal neurons are, there- fore, both voltage and site dependent, revealing the requirement for classes of inhibitory interneurons targeting specific subcellular compartments. Functionally, we suggest that under relatively quiescent (hyerpolarized) conditions, which may occur physiologically during quiescent network conditions (down-states) (Shu et al., 2003), region-specific inhibitory operations will be favored, sculpting local synaptic interactions and controlling the generation of dendritic regenerative activity mediated by activity in coaligned excitatory pathways (Somogyi et al., 1998). During periods of synchronized somato-dendritic excitation that may occur during network-generated up-states (Shu et al., 2003), however, the impact of inhibitory pathways will become less specific, favoring the inhibition of axonal action potential generation by IPSPs generated widely across the apical dendritic arbor. Interaction of IPSPs with voltage-activated channels, therefore, has a powerful and state-dependent influence over the control of inhibitory processing in cortical pyramidal neurons.

\section{References}

Alzheimer C, Schwindt PC, Crill WE (1993) Modal gating of $\mathrm{Na}+$ channels as a mechanism of persistent $\mathrm{Na}+$ current in pyramidal neurons from rat and cat sensorimotor cortex. J Neurosci 13:660-673.

Andreasen M, Lambert JD (1999) Somatic amplification of distally generated subthreshold EPSPs in rat hippocampal pyramidal neurones. J Physiol (Lond) 519:85-100.

Berger T, Larkum ME, Luscher HR (2001) High I(h) channel density in the distal apical dendrite of layer $\mathrm{V}$ pyramidal cells increases bidirectional attenuation of EPSPs. J Neurophysiol 85:855-868.

BoSmith RE, Briggs I, Sturgess NC (1993) Inhibitory actions of ZENECA ZD7288 on whole-cell hyperpolarization activated inward current (If) in guinea-pig dissociated sinoatrial node cells. Br J Pharmacol 110:343-349.

Buhl EH, Halasy K, Somogyi P (1994) Diverse sources of hippocampal unitary inhibitory postsynaptic potentials and the number of synaptic release sites. Nature 368:823-828.

Colbert CM, Pan E (2002) Ion channel properties underlying axonal action potential initiation in pyramidal neurons. Nat Neurosci 5:533-538.

Crill WE (1996) Persistent sodium current in mammalian central neurons. Annu Rev Physiol 58:349-362.

Deisz RA, Fortin G, Zieglgansberger W (1991) Voltage dependence of excitatory postsynaptic potentials of rat neocortical neurons. J Neurophysiol 65:371-382.

Gulledge AT, Stuart GJ (2003) Excitatory actions of GABA in the cortex. Neuron 37:299-309.

Gupta A, Wang Y, Markram H (2000) Organizing principles for a diversity of GABAergic interneurons and synapses in the neocortex. Science 287:273-278.

Halasy K, Buhl EH, Lorinczi Z, Tamas G, Somogyi P (1996) Synaptic target selectivity and input of GABAergic basket and bistratified interneurons in the CA1 area of the rat hippocampus. Hippocampus 6:306-329.

Han ZS, Buhl EH, Lorinczi Z, Somogyi P (1993) A high degree of spatial selectivity in the axonal and dendritic domains of physiologically identified local-circuit neurons in the dentate gyrus of the rat hippocampus. Eur J Neurosci 5:395-410.

Harris NC, Constanti A (1995) Mechanism of block by ZD 7288 of the hyperpolarization-activated inward rectifying current in guinea pig substantia nigra neurons in vitro. J Neurophysiol 74:2366-2378.

Harsch A, Robinson HP (2000) Postsynaptic variability of firing in rat cortical neurons: the roles of input synchronization and synaptic NMDA receptor conductance. J Neurosci 20:6181-6192.

Häusser M, Spruston N, Stuart GJ (2000) Diversity and dynamics of dendritic signaling. Science 290:739-744.

Kawaguchi Y, Kubota Y (1997) GABAergic cell subtypes and their synaptic connections in rat frontal cortex. Cereb Cortex 7:476-486.

Klausberger T, Roberts JD, Somogyi P (2002) Cell type- and input-specific differences in the number and subtypes of synaptic $\mathrm{GABA}(\mathrm{A})$ receptors in the hippocampus. J Neurosci 22:2513-2521.

Koch C, Douglas R, Wehmeier U (1990) Visibility of synaptically induced conductance changes: theory and simulations of anatomically characterized cortical pyramidal cells. J Neurosci 10:1728-1744.

Larkum ME, Zhu JJ, Sakmann B (2001) Dendritic mechanisms underlying 
the coupling of the dendritic with the axonal action potential initiation zone of adult rat layer 5 pyramidal neurons. J Physiol (Lond) 533:447-466.

Lipowsky R, Gillessen T, Alzheimer C (1996) Dendritic Na+ channels amplify EPSPs in hippocampal CAl pyramidal cells. J Neurophysiol 76:2181-2191.

Lorincz A, Notomi T, Tamas G, Shigemoto R, Nusser Z (2002) Polarized and compartment-dependent distribution of HCN1 in pyramidal cell dendrites. Nat Neurosci 5:1185-1193.

Magee JC (1998) Dendritic hyperpolarization-activated currents modify the integrative properties of hippocampal CA1 pyramidal neurons. J Neurosci 18:7613-7624.

Magee JC (1999) Dendritic lh normalizes temporal summation in hippocampal CA1 neurons. Nat Neurosci 2:508-514.

Magee JC (2000) Dendritic integration of excitatory synaptic input. Nat Rev Neurosci 1:181-190.

Miles R, Toth K, Gulyas AI, Hajos N, Freund TF (1996) Differences between somatic and dendritic inhibition in the hippocampus. Neuron 16:815-823.

Nusser Z, Sieghart W, Benke D, Fritschy JM, Somogyi P (1996) Differential synaptic localization of two major $\gamma$-aminobutyric acid type A receptor $\alpha$ subunits on hippocampal pyramidal cells. Proc Natl Acad Sci USA 93:11939-11944.

Nyiri G, Freund TF, Somogyi P (2001) Input-dependent synaptic targeting of $\alpha(2)$-subunit-containing $\mathrm{GABA}(\mathrm{A})$ receptors in synapses of hippocampal pyramidal cells of the rat. Eur J Neurosci 13:428-442.

Oviedo H, Reyes AD (2002) Boosting of neuronal firing evoked with asynchronous and synchronous inputs to the dendrite. Nat Neurosci 5:261-266.

Owens DF, Boyce LH, Davis MB, Kriegstein AR (1996) Excitatory GABA responses in embryonic and neonatal cortical slices demonstrated by gramicidin perforated-patch recordings and calcium imaging. J Neurosci 16:6414-6423.

Pare D, Shink E, Gaudreau H, Destexhe A, Lang EJ (1998) Impact of spontaneous synaptic activity on the resting properties of cat neocortical pyramidal neurons in vivo. J Neurophysiol 79:1450-1460.

Rall W (1977) Core conductor theory and cable properties of neurons. In: Handbook of physiology—-the nervous system 1 (Kandel ER, ed), pp 39-97. Bethesda, MD: American Physiological Society.

Santoro B, Grant SG, Bartsch D, Kandel ER (1997) Interactive cloning with the SH3 domain of N-src identifies a new brain specific ion channel protein, with homology to eag and cyclic nucleotide-gated channels. Proc Natl Acad Sci USA 94:14815-14820.

Shu Y, Hasenstaub A, McCormick DA (2003) Turning on and off recurrent balanced cortical activity. Nature 423:288-293.

Schiller J, Schiller Y, Stuart G, Sakmann B (1997) Calcium action potentials restricted to distal apical dendrites of rat neocortical pyramidal neurons. J Physiol (Lond) 505:605-616.

Schwindt PC, Crill WE (1995) Amplification of synaptic current by persistent sodium conductance in apical dendrite of neocortical neurons. J Neurophysiol 74:2220-2224.
Somogyi P, Tamas G, Lujan R, Buhl EH (1998) Salient features of synaptic organisation in the cerebral cortex. Brain Res Rev 26:113-135.

Steriade M, Timofeev I, Grenier F (2001) Natural waking and sleep states: a view from inside neocortical neurons. J Neurophysiol 85:1969-1685.

Stuart G (1999) Voltage-activated sodium channels amplify inhibition in neocortical pyramidal neurons. Nat Neurosci 2:144-150.

Stuart G, Sakmann B (1995) Amplification of EPSPs by axosomatic sodium channels in neocortical pyramidal neurons. Neuron 15:1065-1076.

Stuart G, Schiller J, Sakmann B (1997) Action potential initiation and propagation in rat neocortical pyramidal neurons. J Physiol (Lond) 505:617-632.

Stuart GJ, Sakmann B (1994) Active propagation of somatic action potentials into neocortical pyramidal cell dendrites. Nature 367:69-72.

Taddese A, Bean BP (2002) Subthreshold sodium current from rapidly in activating sodium channels drives spontaneous firing of tuberomammillary neurons. Neuron 33:587-600.

Tamas G, Buhl EH, Somogyi P (1997) Fast IPSPs elicited via multiple synaptic release sites by different types of GABAergic neurone in the cat visual cortex. J Physiol (Lond) 500:715-738.

Tamas G, Lorincz A, Simon A, Szabadics J (2003) Identified sources and targets of slow inhibition in the neocortex. Science 299:1902-1905.

van Brederode JF, Spain WJ (1995) Differences in inhibitory synaptic input between layer II-III and layer V neurons of the cat neocortex. J Neurophysiol 74:1149-1166.

van Brederode JF, Takigawa T, Alzheimer C (2001) GABA-evoked chloride currents do not differ between dendrites and somata of rat neocortical neurons. J Physiol (Lond) 533:711-716.

Williams SR, Stuart GJ (1999) Mechanisms and consequences of action potential burst firing in rat neocortical pyramidal neurons. J Physiol (Lond) 521:467-482.

Williams SR, Stuart GJ (2000a) Backpropagation of physiological spike trains in neocortical pyramidal neurons: implications for temporal coding in dendrites. J Neurosci 20:8238-8246.

Williams SR, Stuart GJ (2000b) Site independence of EPSP time course is mediated by dendritic Ih in neocortical pyramidal neurons. J Neurophysiol 83:3177-3182.

Williams SR, Stuart GJ (2002) Dependence of EPSP efficacy on synapse location in neocortical pyramidal neurons. Science 295:1907-1910.

Williams SR, Stuart GJ (2003) Role of dendritic synapse location in the control of action potential output. Trends Neurosci 26:147-154.

Williams SR, Christensen SR, Stuart GJ, Häusser M (2002) Membrane potential bistability is controlled by the hyperpolarization-activated current $\mathrm{I}_{\mathrm{H}}$ in rat cerebellar Purkinje neurons in vitro. J Physiol (Lond) 539:469-483.

Xiang Z, Huguenard JR, Prince DA (1998a) Cholinergic switching within neocortical inhibitory networks. Science 281:985-988.

Xiang Z, Huguenard JR, Prince DA (1998b) GABAA receptor-mediated currents in interneurons and pyramidal cells of rat visual cortex. J Physiol (Lond) 506:715-730.

Xiang Z, Huguenard JR, Prince DA (2002) Synaptic inhibition of pyramidal cells evoked by different interneuronal subtypes in layer $\mathrm{v}$ of rat visual cortex. J Neurophysiol 88:740-750. 